\title{
Abu Al-Qasim Az-Zahrawi (325-404AH/936-1013AD)
}

\author{
D. Gassan Mahmud Washah \\ Head of History and Archeology Department at the Islamic University of Gaza
}

"Corresponding Author: Gassan Mahmud Washah, Head of History and Archeology Department at the Islamic University of Gaza.

\begin{abstract}
The Muslim scholar Abu al-Qasim al-Zahrawi is one of the greatest scientists of human history in the field of surgery. He is the founder of the field of surgery, He is the first to use the scalpel in surgery, He invented Many modern surgical instruments are invented by Al-Zahrawi and developed; He was able to manufacture the endoscopy and was able to break the pebbles in the bladder. He also invented the operation chutes from the intestines of the cats, and used them in stomach and intestinal wounds. Al-Zahrawi is the first to do tonsillectomy. All these achievements are documented in the Encyclopedia of Zahrawi in his book "Facilitation for those who can not write", which contains 30 volumes.

Many European scientists testify to the intelligence and virtues of al-Zahrawi such as Gustave Le Bon, ZigridaHonka, Haller and others.
\end{abstract}

\section{INTRODUCTION}

Abu al-Qasim al-Zahrawi is one of the Muslim scholars who have succeeded in their efforts and ideas to elevate themselves and their Islamic civilization. He became the pioneer of surgery at a time when people considered surgery and surgeons to be inferior to their position

This knight and the Arab Imam carried the banner and made it one of the most important medical work has provided many medicines and treatments through surgery and invented more than two hundred surgical instruments did not preceded by one, and his thoughts was an important transformation in his time and became associated with the science of surgery. The most famous of AbiQasim's books is the book "Facilitation for those who can not write" which made him among the great scholars. The Europeans put his picture in their temples on stained glass. The patients called on God to cure them through this man's medicine. He was honored by scholars in the East and West.

\section{THE IMPORTANCE OF THIS RESEARCH}

- The studies that I talked about this subject are few as far as I know.

- Enriching the Arabic library with a distinguished personality has made countless achievements in the field of medicine.

- To see the character of Abu al-Qasim al-Zahrawi and to know what was said by scientists of the East and West, and to know why the star shine in the field of surgeryalone.

- To see the most important pupils who learned from it

- Know the most important medical achievements and tools used in his surgical operations.

- To see his scientific writings and what was said about them.

\subsection{The Limits of the Study}

Time limit: (325/404AH - 936/1013 AD)

The spatial limit: Andalus

\subsection{Study Approach}

The researcher applied the analytical historical research method. 


\section{SECTIONS OF THIS RESEARCH}

The research was divided into an introduction, two chapters and a conclusion, which included the most important findings and proved the sources and references. The first section included an overview of the life of al-Zahrawi and the most important of what was said by scientists in the East and West.

The second section explained some of the medical fields in which Al-Zahrawi worked and mentioned the most important tools he invented and used in his operations. He highlighted some of his books and mentioned the years and places of publication. The research ended with the most important findings and proven sources.

\section{Chapter One: Definition OF Abu AL - QASIM AL -ZAhraWi}

\subsection{First: His Name and Descent}

His name is Khalaf bin Abbas Abu al-Qasim al-ZahrawiAndalusian ${ }^{1}$ AlAnsari, the most famous surgeons and pioneer of Arab medicine, He was born in the city of Zahra and attributed to it and studied medicine on its scientists ${ }^{2}$. Historical sources did not help us with the date of his birth $^{3}$. Some researchers assumed that he was born on $(324 / 404 \mathrm{AH}=936 / 1013 \mathrm{AD})^{4}$, And the title of Balzahrawi because he was born in the city of Zahra and Ansari because the roots belong to the tribes of Alaws and Khazraj, who were help the Messenger of God in his call, as his parents had joined the army of conquest, which opened Andalusia and settled Cordoba ${ }^{5}$, known in Europe as Apolkasis.

Abu al-Qasim is one of the most famous surgeons of Arab surgeons and professor of surgeons in Europe. Al-Zahrawi is the founder of the field of surgery. He wrote the book of facilitation for those who were unable to write, which includes 30 volumes. The sources believe that al-Zahrawi was an expert on medicine, And most famous and has been studying in Europe for many centuries, a testimony to his genius and nobility and excellence in the field of medicine, and the latter part of him talking about surgery and surgical tools used in his work ${ }^{6}$. He was in the time of Ibnsina, And he was one of the doctors who worked in the courts of the two kings, Al-Mustansir and Al-Muayyad. He was mentioned by Hamed bin Samjun and Abu Ubayd Allah Al-Bakri ${ }^{7}$. He was distinguished in medicine and especially in surgery. And IbnSina, who Nbgha in the same field, has been able to invent Zahraoui medical methods in the surgery did not reach them before him, and invented surgical instruments was the first of its kind at that time used in its operations,Some sources say he joined a hospital in Cordoba ${ }^{8}$.

He was fond of reading. He had read my book Al-Hawi and Mansouri of Al-Razi and the Royal Book of the Magusian, the Book of Law for IbnSina, as well as his knowledge of the books of Paul and Ataius Al-Amidi ${ }^{9}$, which helped him to improve his medical character and excellence in medicine. Reading and informed him that enabled him to be sufficiently familiar with diseases and their treatments, He was interested in ways of treating patients and believed that the doctor should do the surgery himself rather than to assign it to other people such as barbers, The doctors were above the surgical operations and considered it a despicable profession does not fit with them and Zahrawi is the first to perform surgery himself, despite the criticism directed at him until he became a flag referred of surgery ${ }^{10}, \mathrm{Al}$-Zahrawi is the reason why the surgery is considered an independent field that does not fall under other medical sciences. The narrations state that he was a man of worship and practiced his work free of charge and his good work and medical literature did not treat women except with a

\footnotetext{
${ }^{1}$ Zirkali Damascene, scholars, $\{2 / 310\}$

${ }^{2}$ Abu Khalil, Shawky, Al-Andalus scholars, their distinguished creations and their impact in the European Renaissance $\{214\}$

${ }^{3}$ Al-Saeed, Abdullah Abdul RazekMasoud, Al-Zahrawi Oral and Dental Surgeon, and his Medical Encyclopedia, $\{10\}$

4 .Sargani, Ragheb, The Story of Medical Sciences in Islamic Civilization \{203\}

${ }^{5}$ Al-Saeed, Abdullah Abdul RazekMasoud, Al-Zahrawi Oral and Dental Surgeon, and his Medical Encyclopedia, $\{10\}$

${ }^{6}$ Al-Dabbi, Ahmed bin Yahya , Objective of the researcher $\{286\}$

${ }^{7}$ Samurai, Kamal, the history of Arab medicine, $\{163\}$

${ }^{8}$ Brokilman, History of Literature, $\{300\}$

${ }^{9}$ Almuqri, history of medicine, $\{136\}$

${ }^{10}$ Haddad, , Abu Al-Qasim Al-Zahrawi, article
} 
midwife ${ }^{1}$. His home was a school and a hospital ${ }^{2}$, It is clear that Al-Zahrawi is rooted in Eastern Arab Arab origins. In the field of surgery, he was mentioned as a result of devouring a large number of the books of his predecessors, which enabled him to excel in them. He became a believer in those who came after him.

\subsection{Secondly: The View of the Scholars from the East and the West about Al-Zahrawi}

Al-Zahrawi is distinguished in the field of medicine, especially surgery, because it was a despised profession in his time. He was quick to see and work on it and move it from a despised profession to a profession that has become important in human life. He has been recognized by Arab and Western scientists as distinguished from other doctors of his time. Al-Zahrawi is the author of knowledge, piety, religion and religion. He is the author of the book The Discharge, the book that was founded for the world of surgery ${ }^{3}$.

"Zigried Honka" described Aba al-Qasim, in her book Shams al-Arab b (great Arab surgeon) and said about him: "The great Andalusian surgeon has introduced many innovations not only in the science of surgery, but in the healing of wounds and surgeons and ophthalmologists and European teeth with the necessary machines for surgery" ${ }^{4}$

Scott said about him: That Aba Al-Qasim is the originator of modern surgery "and put it by Jay de Schuliac in the order of Hippocrates and Galen ${ }^{5}$.

Professor of Major Physiology Haller said about him: That his books were the source of all surgeons of Europe after the fourteenth century" 6

Gustav LeBon said that Abu Al-Qasem is one of the greatest surgeons of history and is credited with breaking the stones in the bladder ${ }^{7}$.

Lucler said that Abu al-Qasim was one of the most famous scholars of the Middle Ages, compared to Hippocrates and Galenus and was mentioned in the institutes of France. And said that he had a lot of experiences that he derived from his private life and considered that the name of Abu Qasim alZahrawi is an expression of Arab surgery ${ }^{8}$.

Western surgical scientists have mentioned Zahrawi in their writings as the greatest surgeon in history and considered his book in surgery to be the greatest author of the Middle Ages ${ }^{9}$.It is clear that alZahrawi received praise in general from the Western scholars who were more correct than the scholars of the East, and that this indicates the importance of al-Zahrawi and his scientific achievements that made Europe study his books and quote doctors and scientists from his books and make him worthy of the title of founder of surgery.

\subsection{Third: Al-Zahrawi Students}

Al-Zahrawi was interested in educating his students. His goal was to establish the scientific bases for them and to convey his scientific message in the best way. He was keen to see this clearly through his method of teaching the students. He recommended that they conduct the surgery themselves. Among his most important students:

- IbenSomayeq (d. $451 \mathrm{AH}$ ) Abu Omar bin Yahya bin Ahmed bin Sumiq Al Qurtubi came down in Toledo and was updated, and he had narrated from Abu Al-Mutraaf bin Fattis and IbnAbiZmayn and applied them, and was strong participating in several sciences, and lived eighty years and was the son of Smiq Al-Zahrawi mentions his teachers ${ }^{10}$.

\footnotetext{
${ }^{1}$ Almuqri, history of medicine, $\{146\}$

${ }^{2}$ Faraj, Izz al-Din, The Virtue of Muslim Scholars on European Civilization, $\{167\}$

${ }^{3}$ Addeeb, Azzahrawi, $\{100\}$

${ }^{4}$ The same resource, $\{279\}$

${ }^{5}$ Ahmed abdul Hay and Sayyed Ahmed, Islamic medicine, $\{90\}$

${ }^{6}$ Lobon, Arabic civilization, $\{40\}$

${ }^{7}$ Lobon, Arabic civilization, $\{490\}$

${ }^{8}$ Loclirk, History of Arabic medicine, $\{1 / 454\}$

${ }^{9}$ Attikriti, Alisnad, $\{201\}$

${ }^{10}$ Azzahrawi in medicine, $\{9\}$ 
- AbinWafid (d. 467H) is the minister of Abu Al-MurtafAbdulrahman bin Mohammed bin AbdulKabir, one of the world's top doctors, especially the individual medicine. He wrote a great book combining the words of Descordis and the saying of Galen. He had a long hand in the treatment ${ }^{1}$ and the residence of Toledo. Ibn al-Nun mentioned that he had planted the garden of the famous Mamounibn Nun in Toledo, and he had gone to Cordoba where he met with Zahraoui and taught on his hands. Among his books is the book of al-Wasasadah in medicine, Rashadad and medical studies $^{2}$.

- Abu Bakr al-Karamani (458 AH) is the father of AlhakamAmribn Ahmed of the scientists of Cordoba excelled in the number and engineering, and traveled to Harran in Iraq and studied medicine and arithmetic, and then returned to Andalusia and lived in Zaragoza and with him the book "Letters of Brothers ofSafa," the first to enter the book in Andalus, He was proficient in ironing, cutting, tightening and bonding ${ }^{3}$.

- Abu Aarab Yusuf bin Mohammed (after 430 years) was an expert in the origins of medicine scientist in the branches, and the age of IbnAbid and son of the Begonsh and was addicted to drinking wine, which affected his relations with his patients ${ }^{4}$.

- Abu Bakr Ahmad bin al-Khayyat (d. 447 e) has experience in the manufacture of medicine and accurate treatment and was a warm and gentle ethics and good biography and cream doctrine and was a scholar of the account and the stars and is a student of Abu QasimMaslama bin Ahmed alMarhaity ${ }^{5}$.

- Joseph ben Ahmed Hassadi (421 e) is a famous doctor of Cordoba and was based on Greek medicine, especially the ideas of Hippocrates, Galenos and Diocrides. He has a book (Explanation of the Book of the Apocrat). He explained the book Aippocrates of a Fatimid khalif, , Was addicted to wine and was fond of humor ${ }^{6}$.

- Abul-hasan bin Abdul Rahman al-Darami (d. 444 e) was educated by Ibn al-Baghonsh, and was adopted in the practice of medicine on the ideas of Hippocrates and Galenos, and worked in the engineering and $\operatorname{logic}^{7}$.

\section{Chapter Two: Zahrawi InNOvations In SURGery}

Al-Zahrawi is the greatest surgeon of the Islamic civilization in the Middle Ages. He has achieved many medical achievements and has excelled in many areas in which he has had the participation and clear touches and additions.

\subsection{First: In The Field of General Surgery}

ZigridHonka said: "About Al-Razi, according to which he is one of the largest surgeons history has inventions and additions to the distinctive surgery, he was the first to sterilize the dead and exhumation of the body to know the causes of death and to benefit from the results and details ${ }^{8}$.

Zohrawi is credited with laying the foundations for the treatment of tumors 9 . He was the first to remove the thyroid gland, which was enlarged as it was one of the strangest and most dangerous surgeries in human life. No surgeon in the world could have performed this operation, this is what surprised European surgeons.

He was the first to carry out the trachea and succeeded in it and is considered a medical preacher, especially when he refrained from doing major medicine in his time, such as Al-Razi and IbnSina.

$\mathrm{He}$ is the first to stop bleeding during surgery by connecting the arteries to each other.

\footnotetext{
${ }^{1}$ Al-Dhahabi, Shams al-Din, Islamic history, $\{10 / 215\}$

${ }^{2}$ The same book, the same page.

${ }^{3}$ Ibnabiosibia, oyonol'anba',$\{484\}$

${ }^{4}$ The same book, $\{495\}$

${ }^{5}$ Ibnabiosibia, oyonol'anba', $\{497\}$

${ }^{6}$ The same resource, $\{500\}$

${ }^{7}$ The same resource, $\{497\}$

${ }^{8}$ Addaffa', Profiles of the history of medicine, $\{66\}$

${ }^{9}$ Ahmed abdul Hay and Sayyed Ahmed, Islamic medicine, $\{91\}$
} 
Al-Zahrawi was the first to use a thread in surgical procedures and tailor it to the surgeon inside without leaving a clear trace ${ }^{1}$ and extracting it from the intestines because the body absorbs it without damage. It is called CAT GUT, which was used in the present era a few years ago ${ }^{2}$.

He was the first to sew the hair on the tail of the horse ${ }^{3}$, Al-Zahrawi taught the doctors to sew two needles with one thread between them ${ }^{4}$.

And talk about the tuberculosis of the artery in the head if the patient suffers from a severe chronic headache.

Al-Zahrawi said that tumors are types and each tumor has its own method of treatment, and tumors should not be eliminated until after the maturity of pus in it and from what should be removed before the maturity of pus especially if it is close to the joint ${ }^{5}$.

Al-Zahrawi discovered cosmetic operations where he explained how surgery in the lip and nose occurs when a large bump protrudes from it. He cuts it back to its normal shape and disappears ${ }^{6}$. He is is the first to alert the precautions to be taken when performing operations to avoid complications ${ }^{7}$.

"Anyone who reads al-Zahrawi's book makes sure that he can be autopsy himself because the way he describes it can not be in his theoretical way," says Portel.

\subsection{Second: Ear, Nose and Throat Surgery}

Al-Zahrawi was able to treat the earal laryngitis that occurs as a result of placing the flies in his eggs in the human ear filled with pus $^{8}$, and treated the accidental dam of the ear. Al-Zahrawi talked about nose surgery and how to remove the plaques ${ }^{9}$, Head injuries and invented tools to open the skull, and had called for sterilization of wounds and used alcohol for that ${ }^{10}$.

\subsection{Third: Eye Surgery}

In this type of surgery, he mentioned a number of surgical instruments that were not preceded by a description of it, such as the iron that specializes in the skin under the eyebrow and the sleigh that was developed for the first time in history to perform surgeries related to "Alsanfara" ${ }^{11}$.

Al-Zahrawi said about the treatment of the lacrimal Nasur and describes the medicine represented in three ways: ironing, pouring the dissolved lead in the hall, and the surgery that is cured from his illness.

The surgery is recommended if the two previous methods fail. The surgery consists of an opening between the lacrimal sac and the nasal mucous membrane across the nose bone. One doctor said that this method was first described in history ${ }^{12}$.

He described the treatment of warts and necks that affect the eyelids and work to remove the cuffs of the excess eyes in one of the four ways either the ironing with fire, either with acute medicine or cutting and sewing or reeds, and described a method of hair removal inside the eye with needle ${ }^{13}$, The treatment that occurs in the lower eyelid or higher called Arnabia and be on two cases either natural or accidental and this is the integration of wound or incision or ironing ${ }^{14}$, and he dealt with treatment of eyelid adhesion cornea and the emergence of excess flesh in the eye ${ }^{15}$ and treatment of the problem of

\footnotetext{
${ }^{1}$ Al-Saeed, A.R Al-Zahrawi, $\{91\}$

${ }^{2}$ Allabdi, History of surgery, $\{89\}$

${ }^{3}$ The same resource, $\{279\}$

${ }^{4}$ Al-Saeed, A.R Al-Zahrawi, $\{10\}$

${ }^{5}$ Zakoor, Azzahrawi medicine, $\{209.218 .224\}$

${ }^{6}$ Sargani, Ragheb, The Story of Medical Sciences in Islamic Civilization, $\{47\}$

${ }^{7}$ Faraj, The Virtue of Muslim Scholars on European Civilization, $\{246\}$

${ }^{8}$ Zakoor, Azzahrawi medicine, $\{150\}$

${ }^{9}$ Ashinqiti, Rulings of Surgery, $\{60\}$

${ }^{10}$ The same resource.

${ }^{11}$ Ashinqiti, Rulings of Surgery, $\{60\}$

${ }^{12}$ Abdul Hay and Sayyed Ahmed, Islamic medicine, $\{91\}$

${ }^{13}$ Zakoor, Azzahrawi medicine, $\{156.157\}$

${ }^{14}$ The same resource.

${ }^{15}$ The same resource, $\{172-174\}$
} 
bumping the eye and treatment using tributaries, a group of The rags that are placed on the eye and then tightened with a hard crotch and keep her eye on as much as you need treatment ${ }^{1}$ and excelled in the Zahraoui glass of water glaze of the eye and mentioned more than six ways to extract from the eye $^{2}$.

\subsection{Fourth: Gynecology and Obstetrics}

Some sources say that al-Zahrawi was complaining about the absence of female doctors or midwives at a high level, which is why he paid attention to surgery in general and women's surgery in particular ${ }^{3}$, and Zahrawi is the first to provide information in the field of obstetrics is an innovation did not precede him, In the treatment and removal of the fetus in the case of the advancement of his hand or knee ${ }^{4}$, the first recommended the birth of the basin called in the gynecological method (Falcher) in the birth and described by Al-Zahrawi precise description, and developed the branch of gynecological diseases to introduce methods of treatment and healing, and created new touches on delivery in the case of Occasional situation, I created a special mirror And developed a machine to expand the uterus ${ }^{5}$, and is the first to cut the water pocket during labor to accelerate the $\operatorname{birth}^{6}$. D. Kamal al-Samarrai said: "He used the catheters to empty the bladder, and the glasses to detect the vagina and used ironing for the treatment"7.

\subsection{Fifth: In the Field of Orthopedic Surgery}

He was the first to learn the art and the art of surgery in the world. He performed the difficult operations from head to foot and used tools of his design and innovation. Al-Zahrawi was the first to care for arthritis in the back beads, which was later called bot, He also described the tools for algebra and fractures and recommended leaving an opening in the plaster hole of the broken and cut man in order to remove the bone. right Now Sound facial when amputation and removal of diseased tissue in bone infections, and was able to describe Gangrene . $^{8}$

\subsection{Sixth: Urology}

Al-Zahrawi was able to develop a fingerprint in this area. He explained the method of incision of the bladder and the introduction of methods to remove the gallstones from the ureter by inserting the file through the urinary tract to the top of the pebble and remove it. By cracking, he mentioned how to remove frozen blood from the bladder after the operation. "He was the first to remove the gravel through the vagina," he said, referring to the importance of placing the border after the opening of the boils and the description of the umbilical hernia, and talked about stopping bleeding by tying or pressing or ironing.

Al-Zahrawi suggested treatment for varicose veins and his method is not very different from the method used by contemporary doctors. One doctor said after mentioning the contents of the surgery: "The method of conducting surgery today is hardly different from what Al-Zahrawi described from ten centuries 9 .

He also invented the catheter. He had invented the catheter in the shape of the letter "S" with two curving steps, making it a unilateral curve ${ }^{10}$. He devised a precise tool to address the problem of obstruction of the urinary incontinence in young children ${ }^{11}$.

\subsection{Seventh: In the Field of Medical Ironing and Cupping}

Al-Zahrawi was one of the first to use this method of treatment. He said: "It is secret to treat the pain and its preference for ironing with the medicine burned, because The fire is a single essence that does

\footnotetext{
${ }^{1}$ The same resource, $\{179\}$

${ }^{2}$ Sargani, Ragheb, The Story of Medical Sciences in Islamic Civilization, $\{46\}$

${ }^{3}$ Samurai, the history of Arab medicine, $\{166\}$

${ }^{4}$ Abu KhalilShawky, Al-Andalus scholars, $\{33\}$

${ }^{5}$ ZigridHonka, Arab sun, $\{279\}$

${ }^{6}$ Samurai, the history of Arab medicine, $\{165\}$

${ }^{7}$ Al-Saeed, A.R Al-Zahrawi, $\{20\}$

${ }^{8}$ Al-Saeed, A.R Al-Zahrawi, $\{19\}$

${ }^{9}$ Ashinqiti, Rulings of Surgery, $\{62-63\}$

${ }^{10}$ Samurai, the history of Arab medicine, $\{165\}$

${ }^{11}$ Sargani, Ragheb, The Story of Medical Sciences in Islamic Civilization, $\{207\}$ 
not exceed its action except the part of the air and the fire of honor does not kill unless it is overfunded and it became clear to me through experience and length of service and stand on the facts of things and that it is not appropriate to write this is not your secret about the fire and how to do in objects and exile diseases with philosophical words You can't understand" ${ }^{11}$.He stressed that it is not permissible for any person to follow the method of ironing with fire unless he is experienced and stopped the moods of people and different ${ }^{2}$, and identified Alzahrawi ironing time, he said it is useful for all time and the use of iron in ironing on gold and explained that if the gold is heated on fire, Some of the blemishes are not clear when gold and iron are hotter in the heat and coldness, so its bounty on gold $^{3}$.

Al-Zahrawi used the medical ironing various diseases such as dementia, headache, nasorrhea, nails, divergence, sciatica, ear and eye aches, forgetfulness due to sputum, hoarseness, tightness of breath, stomach, liver, kidneys, uterus, diarrhea, amputation, liver tumor, hemorrhage and epilepsy. The result is the cutting of the artery ${ }^{4}$. Al-Zahrawi commented on the saying "ironing the last medicine." He said: "It is a valid statement, but we resort to ironing when all the methods we use with the patient fail, such as medicines ${ }^{5}$.

\subsection{Eighth: Oral and Dental Surgery}

Zahraoui referred to the process of cleaning the teeth with iron if the teeth were yellow. Al-Zahrawi spoke about removing the contract from the lips, cutting the excess flesh in the gums, removing the teeth and the origins of the molars, removing the broken jaw and talking about the mesh of the molars with gold and silver threads. In some cases, the bones of cows formed in the form of lentils are used instead of the molten molars, according to some specialized doctors: "Chapter 31 in the extraction of the assets of the molars, and the removal of the broken jaw bones show us the genius of Zahrawi and his ability to innovate, That he wrote about this subject in such detail and accuracy, which shows the enormous experience "and was able to cut the ligament that displays under the tongue and prevent speech, and talked about how to remove the thorns of the throat ${ }^{6}$.

\subsection{Ninth: Other Achievements in Medicine by Al-Zahrawi}

The first to use charcoal in the preparation of simple honey syrup, as well as the first to circumvent the examination of the basin, the first to refer to the incontinence that occurs as a result of cystitis, the first of the images of the surgical instruments used by more than 200 tools $^{7}$.

He also invented a machine that controls the tongue, which is used to hold the tongue during the process of tonsils and advised to make copper or silver and was made in thin form, which is similar to what we are using now for the same purpose, and he is the first to mention the lost heartbeat ${ }^{8}$.

Al-Zahrawi tried to find a solution to cancer by removing the tumor if possible and small in size, but if it is large can not and did not see anyone before him to treat cancer'.

Al-Zahrawi is also known for his knowledge of how to extract oil, vinegar and washing oil, and he can accurately describe how to make a mold of ebony or ivory and engrave granules, Al-Zahrawi said a section of medicinal plants from the author of the book drainage and gave an alphabetical presentation with a lot of vocabulary for these plants, the first to use the drawing forms and images in his book and the method of preparation and preservation of medicines and assigned to each drug a specific container ${ }^{10}$.

It is clear from the above that Al-Zahrawi was able to provide his expertise and services in most medical fields. He came to know new types of diseases that no one had preceded and was able to perform some difficult operations that were considered impossible in his time.

\footnotetext{
${ }^{1}$ Zakoor, Azzahrawi medicine, $\{47\}$

${ }^{2}$ Assaeed, History of Surgery, $\{145\}$

${ }^{3}$ Abo Alqasim tools of surgery, $\{9\}$

${ }^{4}$ Allebdi , History of Surgery, $\{147\}$

${ }^{5}$ Zakoor, Azzahrawi medicine, $\{49\}$

${ }^{6}$ Zakoor, Azzahrawi medicine, $\{209\}$

${ }^{7}$ Allebdi , History of Surgery, $\{279\}$

${ }^{8}$ Samurai, the history of Arab medicine, $\{166\}$

${ }^{9}$ Hosain, the summary of the History of Surgery, $\{119\}$

${ }^{10}$ Faraj, Izz al-Din, The Virtue of Muslim Scholars on European Civilization, $\{169\}$
} 


\subsection{Tenth: Surgical Tools used by Zahrawi in his Work}

The surgeons invented surgical tools that helped them perform their duties and developed the tools they received from the nations that preceded them. They mentioned many of them in their works. The most important books dealing with surgical instruments are the book of drainage for the Zahrawi, the book of the reformist mayor in the surgeon's industry for Abu al-FarajibnYaqoub, And IbnBatlan ${ }^{1}$, and these tools are:

\subsection{Ironing Tools, which are Different Forms Including}

Olival iron : which called like that because of the head like olive, cuneiform head like a nail in which a little bump and in its mouth a small bump, head like a crescent to eyelid, hollow as the body of the eagle feather pipe from the one end that has ironing, iron hole with a lung disease and cough, $\mathrm{A}$ three-sided iron, an iron for the stomach cup, a pen-like iron for a kidney tumor, and a three-piece sciatica round-hook in each other. There are triangular and half-circular irons of the neck hooks, To enter the irons for the internal members' locker ${ }^{2}$.The instruments used in the surgical operations are composed of hooks and one hooks and hooks, and the other three-prongs and one handle to tighten the face, and there are hooks of the broken-jawed and the tip of the triangle is thick and thick, and it removes the molars from their roots ${ }^{3}$.

The scalpels: which is different in its different forms. There is a scalpel that is sharp on both sides. It is used to open a place in the skin above the arteries so that the surgeon can connect it. The scalpel is one of the extremities and is used to remove the tonsils. In the case of the tumor to allow the introduction of a small tube to withdraw water, and another scalpel cut by the palms, and a scalpel to open the tumors to extract the pus, and the soft scalpel and is used in cutting the excess weft in the eyelid, and a scalpel to cut what enters the ear of foreign objects, and a scalpel used to remove the pebble, , And Another condition is used to open the ear that clog either by the excess plant or through the entry of a foreign body ${ }^{4}$.

There are "Tubes" : that were made of feathers or made of copper or iron depending on the type of function performed, there is a tube to cut the polyps that grow in the face and neck and made of eagle feathers, the ear tube is a narrow nose and a wide end and is used to clean the ear It is made of silver or copper, and there is a tool like a shovel to scrap the foreign objects from the ear and use the "peat" to extract the delicate objects from the ear'.

And one of the tools used in the delivery is the "uterine coil", which is made of Ebony and is used in the opening of the uterus, and there are two fingers to extract the fetus and uses a hatchery is a scissors-like machine and the fetal head is hard to remove it from the mouth of the uterus, and also used fetal cannon and pinned fetus and push it outside the $w_{0 m b}{ }^{6}$.

Al-Zahrawi used tools to scrape teeth and clean them from caries and some used for inventory from the inside and there is a type of inventory between the teeth and other type of inventory between teeth, and there is a kind used to scrape bones ${ }^{7}$.

The surgeons used a tool made of copper and are in three forms, including small and large and medium and be cylindrical shape and used to cut bleeding, including the firearm and water, syringes are two large and small and the last used for children is made of silver or copper ${ }^{8}$, There is a tool used used to distill water in the bladder cavity and it contains three holes, and there is manifold, which is a triangular machine made of solid iron and has a wooden handle used to break the pebble in the urethra, A tool is made of brass, white or lead and is used for piercing the ear of the conjunctiva and then uses the drill tool, and the use of a machine to probe and investigate tumors, which is on three sizes large, small and medium, There is a scalpel, which was used in oncology surgery and is on three

\footnotetext{
${ }^{1}$ Sargani, Ragheb, The Story of Medical Sciences in Islamic Civilization, $\{48\}$

${ }^{2}$ Allebdi , History of Surgery, $\{241\}$

${ }^{3}$ Sargani, Ragheb, The Story of Medical Sciences in Islamic Civilization, $\{49\}$

${ }^{4}$ The same resource, $\{49\}$

${ }^{5}$ Sargani, Ragheb, The Story of Medical Sciences in Islamic Civilization, $\{50\}$

${ }^{6}$ The same resource, $\{51\}$

${ }^{7}$ The same resource, $\{52\}$

${ }^{8}$ The same resource, $\{53\}$
} 
sizes, and invented a machine to fix the tongue Zahraoui so that the surgeon can see the throat and detect the tumors, A tool was used to lift the eyelid during the operation, controlling water from the eye, and used shears to cut what remains of the skin in the operations of the eyes and there are scissors sterilization, which is used to clean the eye after the operation ${ }^{1}$.The pyram is one of the medical tools they used for orthopedic surgery through bone response from the fracture ${ }^{2}$.

We conclude from the above that Zahrawi was able to describe new surgical instruments that were not known before helped to heal many patients in his time and some are still used today.

\subsection{Eleventh: The Works of Al-Zahrawi (Books)}

\section{Al-Zahrawi Wrote Many Medical Books, Including}

$>$ The book of interpretation of weights, published by Abdul Hamid Alouji in Baghdad in 1976, and is believed to be part of the missing parts of the book discharge ${ }^{3}$.

$>$ Useful speech in the science of surgery, translated into Latin under the name (surgery of Abu Qasim), and published in Arabic version with the English version in Oxford $1778^{4}$.

$>$ A brochure about gynecology ${ }^{5}$.

$>$ A book containing the names of the types of medicine in Greek, Syriac, Persian, and Ajami, and interpretation of weights and weights, and drug allowance, and the interpretation of names in the medical books ${ }^{6}$.

$>$ Zarkali mentioned the following: (and in the closet Rabat (93 Glauly) a small book, in which the abbreviated vocabulary ofKhalaf the son of Abbas Al-Zahrawi and its characteristics ${ }^{7}$.

\section{THE BOOK OF "ATTASREEF" FACILITATION FOR THOSE WHO CAN NOT WRITE}

Al-Zahrawi excelled in the art of surgery until his surgical work became the first reference for Arab and European doctors for several hundred years. His surgical innovations promoted this specialty, At the time, Europe was humiliated by the decisions of the Church, which forbade the teaching of surgery in medical schools, and described the doctors who practice them as despicable and unfaithful. Therefore, Arab medical historians agreed that only Arabs, especially Zahrawi, were the first to develop surgery in its new sense. "With its book" The sun of the Arabs shining on the West, "she says:" This particular branch owes the Arabs their progress and ascendance from the rank of the butcher to the top., And to them alone thanks to the lifting of this great art of the level that deserves, and preferred survival. "The book of "Attasreef ", which is one of the most famous and largest and contains more than thirty parts.

Many doctors quote from this book the advice and observations written by Al Zahrawi, including De Claudius, the Italian doctor Ferri and Mazzio de Gradillas, and there is the Italian doctor Sondos de Ardosiris, who published a book on toxins and in each page mentioned the name of al-Zahrawi, Ibn al-Bitar benefited from al-Zahrawi on how to extract oil.

His book included many pictures of the 200 machines and surgical instruments he invented by himself, such as: birth dentures, vaginal endoscopy, injection syringe or regular injection, enema, tongue reduction, guillotine guillotine, Toothpicks, tooth saws, bone saws, irons of all kinds, not to mention dozens of blisters, jabs, spiders, scaffolds, and sensors. And is supported by many of the surgical tools he used in his work.

The book gained considerable interest in Europe and they studied the book in European universities for many centuries. It was translated into Hebrew and Latin and his book had a great influence in the renaissance of Europe where his doctors came back to benefit from it. His book received great acclaim in Europe, "When the book of (the major surgery) took more than 200 paragraphs mentioned

\footnotetext{
${ }^{1}$ Sargani, Ragheb, The Story of Medical Sciences in Islamic Civilization, $\{53\}$

${ }^{2}$ The same resource, $\{53\}$

${ }^{3}$ Samurai, the history of Arab medicine, $\{167\}$

${ }^{4}$ The same resource, $\{69\}$

${ }^{5}$ Brokilman, History of Literature, $\{4 / 303\}$

${ }^{6}$ Zirkali Damascene, scholars, $\{2 / 310\}$

${ }^{7}$ Zirkali Damascene, scholars, $\{2 / 311\}$
} 
by al-Zahrawi, and it is noteworthy that surgery was a despised profession in Europe and was banned from the papal compound and were describing European doctors with the butchers because it is not worthy of respected doctors ${ }^{1}$.

Al-Zahrawi said that he took the sources of his writings in medicine on the flags of medicine in his time, such as IbnMasawi and Habish al-Asim, Masrjawy al-Basri, IbnRabban al-Tabari, IbnNawah alQamri, IbnBillan, IbnJaljal, IbnJizla al-Baghdadi, Ali ibn 'Issa al-Kahhal, IshaqibnOmran and alGhafaki. , And he mentioned his scientific experiences beside every subject he wrote, and recommended the need to know anatomy because it is the basis of each surgery and ignorance of it leads to serious consequences ${ }^{2}$.

Al-Zahrawi divided the book into three sections, containing thirty sections. The first section included the medical colleges and the second section on diseases and their causes from head to foot, such as hemorrhoids, rheumatism, toxins, skin diseases and diets. The third section included explanation of simple and complex medicines, And mentioned important data on the history of medical and chemistry and manufacturing ${ }^{3}$, and specialized the last part of surgery and talk about the ironing and methods in the treatment of patients, where he explained the types of diseases and irons used for treatment and focused on exercise before starting work, She works in folk medicine to this day, and Al-Zahrawi has assigned him fifty-six chapters ${ }^{4}$.

The first part of the book was translated into Latin by Alkarmooni for Section 30 in the twelfth century, including the transfer of Hebrew by Sha'im Top and the printing of the whole book of the Latin language in Kutenberg in 1915. L 1274, and another copy is found in the libraries of Goethe, Baudliana and the National in Paris France, and there is a copy in the library of Hantankton and the Iraqi Museum ${ }^{5}$, and the surgical section was printed in his Arabic language in Hyderabad in 1908 and there is a Turkish translation by SabungiogluSharafuddin ${ }^{6}$.

These are some of the achievements that have come to us from this glorious scientist, which deserves appreciation for his knowledge. It showed the extent of civilization and development that the Muslims attained in his time, despite the simplicity of the tools he used. We are impressed by his creations in all fields of medicine. In the world, his disciples followed his medical guidance, such as: De Choliac, who was so affected by Zahraoui that he abandoned the use of pesticides and returned to use ointments. Because of al-Zahrawi and scholars, Islamic civilization had its place among nations.

\section{CONCLUSIONS AND RECOMMENDATIONS}

\section{The Study Reached a Number of Results, The Most Important of them are}

- Al-Zahrawi was born in the city of Al-Zahra Andalusia and his roots are rooted in the tribes of AlAus and Al-Khazraj Al-Ansariyen and is famous in Europe as Apolixis.

- Al-Zahrawi was fond of reading books. He read for Razi, IbnSina, Paul and Atheus, which gave him a huge medical fortune that had a role in his brilliance.

- Al-Zahrawi emerged in the field of surgery and his foundation was considered as the race to discover new diseases and treatments that were previously unknown such as thyroid surgery and the blue water tank of the eye.

- Because of the medical genius of the medical specialty of Al-Zahrawi, he was able to win many confessions from Arab and Western historians and surgeons about his creativity in the field of surgery such as Lubon, ZigridaHonka, Haller and Scott.

- Al-Zahrawi was interested in his students, and his mission was to deliver his scientific message in the best way. Among the most famous of his disciples is IbnSamiq, IbnWafid and others.

\footnotetext{
${ }^{1}$ Hijazi, Abdullah, one of the most famous medical scientists "Al-ZahrawiAndalusian", the site of Alouka.

${ }^{2}$ Faraj, Izz al-Din, The Virtue of Muslim Scholars on European Civilizatio, $\{169\}$

${ }^{3}$ Faraj, Izz al-Din, The Virtue of Muslim Scholars on European Civilizatio, $\{169\}$

${ }^{4}$ Allebdi , History of Surgery, $\{279\}$

${ }^{5}$ Samurai, the history of Arab medicine, $\{168\}$

${ }^{6}$ The same source, $\{169\}$
} 
- Al-Zahrawi is a comprehensive physician who has provided many treatments in his surgery such as ophthalmology, urinary tract surgery and pediatric problems, and used in his surgeries filaments from the intestines of the cats and excelled in suturing two needles and one thread.

- Zahrawi used an excellent method in the process of abdominal surgery, and was the first to use the method of connecting arteries in surgery to stop bleeding.

- Al-Zahrawi used many surgical instruments in his operations such as scalpels, irons, teeth, saws, tweezers.

Al-Zahrawi was characterized by his work as practical he was able to distinguish between simple and malignant tumors. Al-Zahrawi was keen to write down all that he was doing by relying on his practical experiences. He wrote many of the most famous books, "Al-Tasrif", which made a quantum leap in the world of surgical medicine in Europe. wich translated to several languages and the Europeans quoted many quotations.

\section{SOURCES AND REFERENCES}

\section{First: Sources}

[1] IbnAbiOsaibia, Ahmed bin Qasim bin Khalifa bin Younis Al KhazrajiMowafaq al-Din, (d. 668 e)\ News in the layers of doctors, T: NizarReda, Library of Life - Beirut - Lebanon.

[2] Al-Dhahabi, Shams al-Din Abu Abdullah Muhammad bin Ahmed bin Othman IbnQaimaz al-Zahabi (d. 748 e)

[3] History of Islam and the death of celebrities, Bashar al-Wad well known, Dar al-Gharb al-Islami, first edition, 2003.

[4] Haji Khalifa, Mustapha bin Abdullah, writer of Chalabi Constantinople, (1067 AH) / revealed suspicions about the names of books and arts, Muthanna Library, Baghdad,

[5] Zirkali Damascene, Khairuddin bin Mahmoud bin Mohammed bin Ali bin Fares (1396 AH), \ scholars, Dar Al-Ilm for millions, the fifteenth edition, 2002.

[6] Al-Dabbi, Ahmed bin Yahya bin Ahmed bin Omairah (T 599 e) $\backslash$ Objective of the researcher on the history of the people of Andalus, Dar al-Kitab al-Arabi, Cairo, 1967.

\section{Second: References}

[1] Abu Khalil, Shawky, Al-Andalus scholars, their distinguished creations and their impact in the European Renaissance, Dar Al-Fikr, Damascus, 2004

[2] Ahmed, Abdel Razek Ahmed, Islamic Civilization in the Middle Ages, Dar Al-Fikr Al-Arabi, Cairo, First Edition, $1991 \mathrm{AD}$

[3] Samurai, Kamal, the history of Arab medicine, Dar Nidal, 1984.

[4] Sargani, Ragheb, the Story of Medical Sciences in Islamic Civilization, Iqra Foundation, Cairo, First Edition, 2006.

[5] Al-Saeed, Abdullah Abdul RazekMasoud, Al-Zahrawi Oral and Dental Surgeon, and his Medical Encyclopedia, First Edition, Amman, 2001.

[6] Al-Labadi, Abdul Aziz, History of Surgery among Arabs, Dar al-Carmel, Amman, 1992

[7] Hussein, Mohamed Kamel, Summary of the History of Medicine and Pharmacy among Arabs, Arab Organization for Education and Culture and science

[8] Zakur, Mohammed Yasser, Zahrawi in the medical profession, the Syrian General Organization for Books, Damascus.

[9] Faraj, Izz al-Din, The Virtue of Muslim Scholars on European Civilization, Dar Al-Fikr Al-Arabi, Cairo, 2002.

[10] Leopon, Gustav, Civilization of the Arabs, cared for by Adel Zuaiter, Egyptian General Book Authority, Cairo, 1969

[11] Honke, Ziegried, Religion Shines on the West, Translation of the Differences of Beydoun and Kamal Dasouki, Dar Sader, Beirut, 10th Edition, 2002.

\section{Scientific Sites and Articles}

- Hijazi, Abdullah, one of the most famous medical scientists. Al-ZahrawiAndalusian, the site of Alouka 
- Haddad, Abdel-Hafeez, Abu Al-Qasim Al-Zahrawi

AUTHOR'S BIOGRAPHY

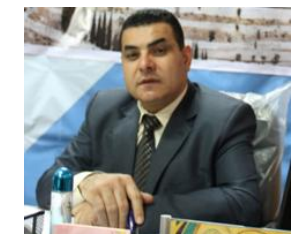

D. Ghassan Mahmoud Washah Head of History and Archeology Department at the Islamic University of Gaza

Citation: D. Gassan Mahmud Washah. “Abu Al-Qasim Az-Zahrawi (325-404AH/936-1013AD)”. International Journal of History and Cultural Studies (IJHCS). vol 4, no. 2, 2018, pp. 25-36. doi:DOI: http://dx.doi.org/ 10.20431/2454-7654.0402003.

Copyright: () 2018 Authors. This is an open-access article distributed under the terms of the Creative Commons Attribution License, which permits unrestricted use, distribution, and reproduction in any medium, provided the original author and source are credited. 